\title{
Supplemental Information for Environmental Risks of Nanotechnology: National Nanotechnology Initiative Funding, 2000-2004
}

\author{
Katherine A. Dunphy Guzmán*1,2, Margaret R. Taylor ${ }^{*}$, Jillian F. Banfield, ${ }^{1,2}$ \\ ${ }^{1}$ Department of Earth \& Planetary Science, University of California, Berkeley, CA 94720-4767 \\ ${ }^{2}$ Earth Sciences Division, Lawrence Berkeley National Laboratory, Berkeley, CA 94720 \\ ${ }^{3}$ Goldman School of Public Policy, University of California, Berkeley, CA 94720-7320 \\ * Corresponding author: kadunphy@berkeley.edu
}

\section{Nanomaterials and products}

Commercial product examples of nanomaterials include clothing (Eddie Bauer, Nano-Care ${ }^{\mathrm{TM}}$ ), bicycle parts (Easton Bicycle Products Group, CNT Composite Enhanced Resin System ${ }^{\mathrm{TM}}$ ), paint (Mercedes-Benz), and anti-bacterial coatings on kitchen appliances (Samsung Electronics, Silver Nano Health System ${ }^{\mathrm{TM}}$ ). Table SI provides a list of nanomaterials with current and proposed applications.

Table SI. Nanomaterials and applications.

\begin{tabular}{|c|c|}
\hline Nanomaterial & Applications: current and proposed \\
\hline Aluminum & Propellant and explosive additives \\
\hline Aluminum oxide & Scratch-resistant coatings, abrasives for polishing \\
\hline C60 (bucky balls) & Drug delivery, biosensors, coatings, energy transmission \\
\hline Cadmium selenide, cadmium sulfide & Biological probes \\
\hline Cadmium telluride & Photovoltaics \\
\hline Calcium phosphate & Insulin, vaccines, artificial implants, bone fillings \\
\hline Carbon nanotubes & $\begin{array}{l}\text { Bicycle components, golf clubs, tennis rackets, electronics, sensors, } \\
\text { energy storage, data storage }\end{array}$ \\
\hline Cerium oxide & $\begin{array}{l}\text { Gasoline additive, general catalyst, abrasive for polishing, cigarette } \\
\text { product manufacturing }\end{array}$ \\
\hline Chromium oxide & Catalyst \\
\hline Cobalt iron oxide & Data storage \\
\hline Copper & Automotive lubricant additive \\
\hline Gold & $\begin{array}{l}\text { Nanoelectronics, Biosensors, catalysts (pollution control, fuel cells), } \\
\text { coatings }\end{array}$ \\
\hline Iron & Environmental remediation \\
\hline Iron oxides & Environmental remediation, paint, drug delivery \\
\hline
\end{tabular}




\begin{tabular}{ll}
\hline Palladium & Catalysts \\
Silica & $\begin{array}{l}\text { Tennis rackets, polyester fibers, wrinkle remover cream, coatings, drug } \\
\text { delivery }\end{array}$ \\
Silver & Anti-microbial coatings (socks, kitchen appliances, bandages) \\
Tin oxide & Scratch-resistant coatings \\
Titanium dioxide & Paint, catalysts, photovoltaics, cosmetics, sunscreens \\
Zinc oxide & Sunscreens, UV-absorbing glass coatings \\
Zinc sulfide & Biological probes \\
Zirconia & Dental restoratives, optical coatings \\
\hline
\end{tabular}

\section{Government Discussions of the Risks of Nanotechnology}

The National Science and Technology Council was established by Executive Order on November 23, 1993 to serve as a cabinet-level means for the President to coordinate the diverse parts of the federal research and development enterprise. In 1996, the U.S. government established an informal working group to evaluate the potential of nanotechnology. In one of the earliest examples of official reports dealing with the topic of environmental risks of nanotechnology, the predecessor to today's Nanoscale Science, Engineering, and Technology (NSET) Subcommittee of the National Science and Technology Council, discussed the pollution potential of nanoparticles as well as the issue of mitigation in its 1999 report on the research vision for nanotechnology (1). One report (10) called for the study and control of nanoprocesses with respect to the environment as well as interdisciplinary research on the topic, including longterm effects of the technology.

One of the nine "Grand Challenge" areas that guides the strategic plan for the NNI is "Nanoscale Processes for Environmental Improvement" (2). Although this Grand Challenge area is often referred to when discussing the government role in addressing the impact of nanotechnology on the environment, for the most part, this area has focused on either the positive impacts that nanotechnology can have on environmental issues or on basic research related to non-engineered nanoparticles, exemplified by our analysis discussed in General Results and in Figure 1.

The focus on the positive seems to have shifted since 2003, with the implications of nanotechnology for natural and global processes and human health receiving greater attention from the federal government (3). Since 2003, the Environmental Protection Agency (EPA) has helped organize "Nanotechnology and the Environment" sessions at the American Chemical Society National Meetings, which have included environmental policy and nanotoxicology research. In 2004, the National Science Foundation (NSF) co-sponsored an international meeting that highlighted the need for early risk assessment of nanotechnology (4). Also in 2004, the Office of Science and Technology Policy and the Office of Management and Budget issued a memorandum outlining research and development (R\&D) budget priorities for nanotechnology, stating that agencies "should place a high priority on research on human health and environmental issues related to nanotechnology and develop, where applicable, cross-agency approaches to the funding and execution of this research" (5). This was followed by the release of the 2004 NNI Strategic Plan, which stated that one of its four goals is to "support responsible development of nanotechnology"; this includes the environmental, health and safety implications of nanotechnology as well as the technology's ethical, legal, and other societal dimensions (6). The recent emergence of the Interagency Working Group on Nanotechnology Environmental and 
Health Implications also reflects an increased focus on the environmental risks of nanotechnology. Most recently, the Institute of Medicine of the National Academies released a report on the environmental health implications of nanotechnology (7), highlighting the need for further research and regulation of nanotechnology as well as cooperation between interested parties to address issues of risk.

\section{Methodological Details of Funding Analysis}

In our analysis, award amounts are attributed to the year in which the award was given, rather than to the year of the solicitation. In collecting data, we used multiple keyword searches, checked resulting data for duplications and relevancy, and compared all funding data from specific agencies against the NNI website for accuracy. Although the Lawrence Berkeley National Laboratory (LBL) has internally funded a project to investigate the environmental implications of nanotechnology, its parent agency, the Department of Energy, does not report any nanotechnology funding amounts for environmental and health and safety research to the NNI. Likewise, National Aeronautics and Space Administration (NASA) has internally funded a study on the toxicity of nanoparticles but does not report this amount to the NNI. The LBL and NASA research funding is not included in our R\&D analysis, but it would amount to less than $1 \%$ of all $\mathrm{NNI}$ reported environmental research if we were to include it.

\section{Category Definitions of Funding Analysis}

Basic knowledge/research involves fundamental environmental nanoscience research of nanoparticles, including structure, size, shape, properties and reactivity. Tools for nanoenvironmental research encompasses tools for characterization, monitoring, identification, and containment of nanomaterials in environmental contexts. Environmental implications of nanoparticles are the causal effects of introducing nanoparticles into the environment, including toxicity, fate, transport, exposure, global impact, and life cycle analyses. Environmental applications using nanotechnology are positive applications for environmental improvement using nanotechnology, including remediation. Green manufacturing of nanotechnology is the development of environmentally friendly manufacturing processes for nanotechnology products, minimizing waste and pollution.

Engineered nanoparticles are those manufactured for commercial and/or research use, such as quantum dots, carbon nanotubes, fullerenes, and metal oxides. Natural nanoparticles are those found in nanoparticulate form in nature, in their naturally-occurring environment and concentration. Natural nanoparticles include many minerals and mineral composites as well as products of natural processes such as volcanic ash, forest fire smoke, and ocean spray. Incidental nanoparticles are those that are a by-product of human activities, such as products of combustion, sandblasting, and metal working. Adopted from Colvin (8).

\section{References}

(1) Flagan, R.; Ginley, D. S. Nanoscale Processes in the Environment. In Nanotechnology Research Directions: IWGN Workshop Report-Vision for Nanotechnology Research and Development in the Next Decade; Roco, M. C., Williams, S., Alivisatos, P., Eds.; Kluwer Academic Publishers: Norwell, MA, 1999; pp 143-152.

(2) "The National Nanotechnology Initiative: The Initiative and Its Implementation Plan," National Science and Technology Council's Committee on Technology, Subcommittee on Nanoscale Science Engineering and Technology, 2000.

(3) "Nanotechnology Grand Challenge in the Environment: Research Planning Workshop Report, Vision for Nanotechnology R\&D in the Next Decade," The National Science and Technology Council Subcommittee on Nanoscale Science, Engineering and Technology, 2003. 
(4) "International Dialogue on Responsible Research and Development of Nanotechnology Report," National Science Foundation and Meridian Institute, 2004.

(5) Marburger, J. H.; Bolten, J. B. "Memorandum for the Heads of Executive Departments and Agencies: Updated Administration Research and Development Budget Priorities," Office of Science and Technology Policy, Office of Management and Budget, August 12, 2004.

(6) "The National Nanotechnology Initiative Strategic Plan," Nanoscale Science, Engineering and Technology Subcommittee, Committee on Technology, National Science and Technology Council, 2004.

(7) "Implications of Nanotechnology for Environmental Health Research," National Academies Press, 2005.

(8) Colvin, V. Research Vision: Sustainability for Nanotechnology. The Scientist 2004, 18. 